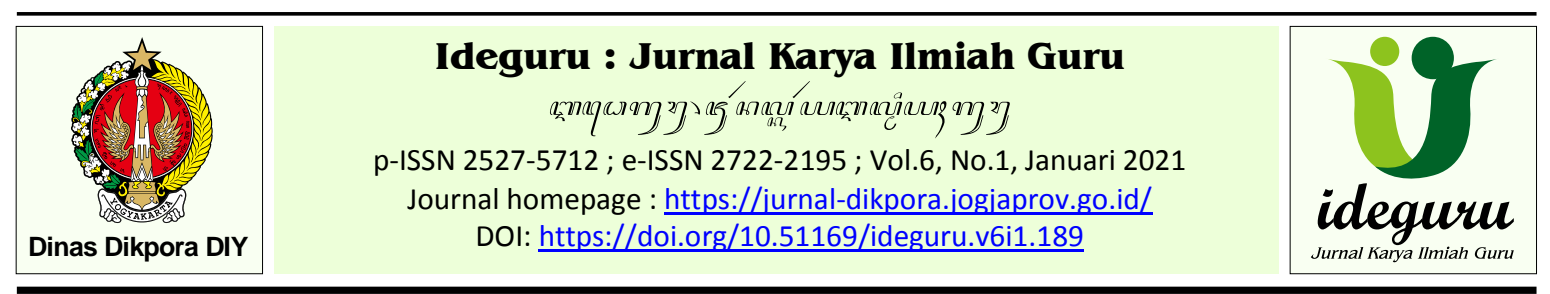

Best Practice - Naskah dikirim: 30/12/2020 - Selesai revisi: 12/01/2021 - Disetujui: 13/01/2021 - Diterbitkan: 15/03/2021

\title{
Penerapan Strategi “Pair System" Untuk Meningkatkan Validitas Penelusuran Lulusan
}

\author{
Bujang Sabri ${ }^{1}$, Eko Mulyadi ${ }^{2}$ \\ ${ }^{1,2}$ SMK Negeri 3 Yogyakarta \\ ${ }^{1}$ bujangsabri@smkn3jogja.sch.id ${ }^{2}$ mwdijohardimulyo@gmail.com
}

\begin{abstract}
Abstrak: Tracer study merupakan strategi melacak lulusan agar diperoleh data yang valid, jumlah yang bekerja, wirausaha dan melanjutkan kuliah. Strategi "Pair System" adalah proses pelacakan alumni dengan melibatkan siswa baru mencari pasangan dengan wilayah terdekat guna meningkatkan data lulusan yang lebih update/terkini. Tujuan dari penerapan Pair System dalam penelusuran lulusan untuk mendeskripsikan strategi peningkatan validitas penelusuran lulusan melalui Pair System dan peta kebekerjaan lulusan sesuai kompetensi. Metodenya, siswa baru dipasangkan dengan alumni terdekat, bisa melalui komunikasi digital dan ataupun home visit, selain juga memperoleh informasi, siswa baru memperoleh pengalaman belajar dari alumni. Strategi Pair System ini telah melalui proses analisis mikro dan makro sekolah selanjutnya dilakukan analisis SWOT yang memperhatikan kekuatan, kelemahan, peluang dan tantangan serta dijabarkan dalam matrik SWOT. Hasil penerapan strategi penelusuran Pair System diperoleh $72 \%$ menjadi 93\%, ada kenaikan 21\%, sedangkan hasil kebekerjaan lulusan dengan strategi ini 52\% menjadi 72\%. Kebekerjaan sesuai kompetensi keahlian yakni keahlian Teknik Kendaraan Ringan dari terserap 41\% menjadi 72\%, Teknik Pemesinan 50\% menjadi 70\%, Teknik Instalasi Tenaga Listrik dari 33\% menjadi 68\%, Teknik Audio Video 36\% menjadi $68 \%$, desain pemodelan dan informasi bangunan $43 \%$ menjadi $52 \%$. Penerapan strategi dapat meningkatkan validitas penelusuran dan kebekerjaan, serta bermanfaat menjalin ikatan kekeluargaan terutama kompetensi, komunikasi dan networking.
\end{abstract}

Kata Kunci: pair system, siswa baru, alumni

\section{Implementation of the "Pair System" Strategy to Increase Validity of Graduates Tracking}

\begin{abstract}
Tracer study is a strategy to trace graduates in order to obtain valid data, the number of employed, entrepreneurship and continuing college. The "Pair system" strategy is a process of tracking alumni by involving new students looking for a partner in the closest area in order to increase the more updated / recent graduate data. The purpose of implementing the Pair System in graduate tracing is to describe the strategy for increasing the validity of graduate tracing through the Pair System and the graduate employment map according to competence. The method is, new students are paired with the closest alumni, either through digital communication and / or home visits, in addition to obtaining information, new students gain learning experiences from alumni. The "Pair System" strategy has gone through a process of micro and macro analysis of the school and then a SWOT analysis is carried out which takes into account the strengths, weaknesses, opportunities and challenges and is described in the SWOT matrix. The results of applying the Pair System tracing strategy were obtained $72 \%$ to 93\%, there was an increase of $21 \%$, while the results of the graduates' employment with this strategy were $52 \%$ to $72 \%$. Work according to skill competencies, namely Light Vehicle Engineering expertise from $41 \%$ absorbed to $72 \%$, Mechanical Engineering 50\% to 70\%, Electrical Power Installation Engineering from 33\% to 68\%, Audio Video Engineering 36\% to 68\%, modeling design and building information $43 \%$ to $52 \%$. The implementation of strategies can increase the validity of tracing and employment, and is useful for building family ties, especially competence, communication and networking.
\end{abstract}

Keywords: pair system, new students, alumni 


\section{Pendahuluan}

Menurut Undang Undang Nomor 20 Tahun 2003 dalam penjelasan Pasal 15 tentang Sistem Pendidikan Nasional, Sekolah Menengah Kejuruan merupakan pendidikan menengah yang mempersiapkan peserta didik terutama untuk bekerja. (Supriyadi, Adang Suryana, 2020).

Salah satu tanda keberhasilan SMK adalah dilihat dari bagaimana lulusan atau alumninya bisa terserap di dunia kerja atau bisa melanjutkan ke jenjang pendidikan yang lebih tinggi. Keberhasilan tersebut bukan datang dengan sendirinya tetapi perlu ada upaya yang holistic dari pihak sekolah untuk menyiapkan anak didiknya (Sriyono, 2016).

Sayangnya hingga saat ini lulusan SMK masih tercatat sebagai penyumbang pengangguran terbesar dibanding dengan jenis pendidikan setara lainnya, maka kami merasa perlu adanya penelusuran lulusan/tamatan (Tracer study) untuk mendapatkan data gunakan memetakan kondisi lulusan/tamatan sehingga kebijakan kebijakan yang diambil untuk pengembangan berkelanjutan lebih tepat dan lebih manfaat.

Nampak data BPS (Februari 2019), tingkat pengangguran terbuka berdasarkan pendidikan tertinggi adalah SMK sebesar 8,63\%. Tracer Study sangat penting untuk mendapatkan data yang valid dan akurat.

Di Indonesia, pelaksanaan Tracer Study umumnya masih terkendala di sisi kebutuhan, sumber daya dan metodologi dalam pelaksanaannya. Seringkali Tracer Study dilakukan oleh Sekolah hanya karena kebutuhan akan akreditasi, sehingga pelaksanaannya tidak dilakukan secara rutin. Selain itu, sumber daya pelaksana Tracer Study umumnya masih dianggap kurang memadai dan hal ini disertai dengan kesulitan dalam menerapkan metodologi yang tepat dalam pelaksanaannya.

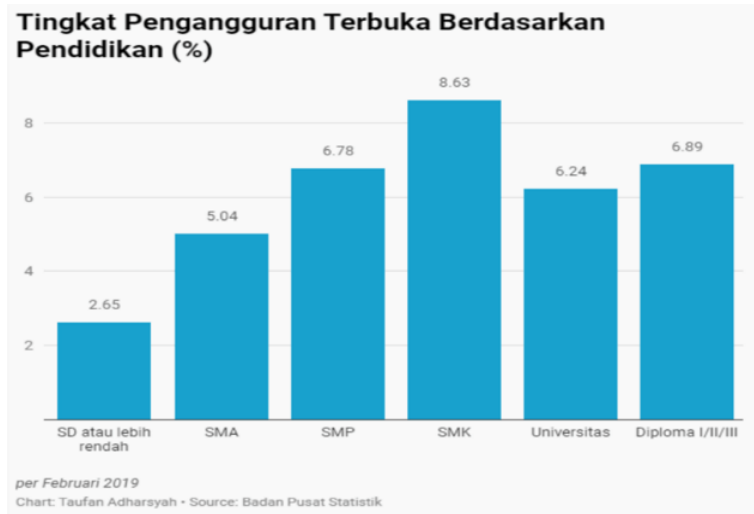

Gambar 1. Tingkat Pengangguran Terbuka (https://www.gamelab.id/news/121 pengangguranterbanyak-disumbang-oleh-smk-ini solusinya)
Tabel 1. Perkembangan Tracer Study SMKN 3 Yogyakarta

\begin{tabular}{ccc}
\hline $\begin{array}{c}\text { Tahun } \\
\text { Pelaksanaan }\end{array}$ & Angkatan & $\begin{array}{c}\text { Teknik } \\
\text { Pelaksanaan }\end{array}$ \\
\hline 2015 & $2012,2013,2014$ & $\begin{array}{c}\text { Penyebaran } \\
\text { kuesioner melalui } \\
\text { email attachment }\end{array}$ \\
\hline 2016 & $2013,2014,2015$ & $\begin{array}{c}\text { Penyebaran } \\
\text { kuesioner melalui } \\
\text { email attachment }\end{array}$ \\
\hline 2017 & $2014,2015,2016$ & $\begin{array}{c}\text { Sistem } \\
\text { kuesioner online }\end{array}$ \\
\hline 2018 & 2016,2017 & $\begin{array}{c}\text { Sistem } \\
\text { kuesioner online }\end{array}$ \\
\hline 2019 & 2017,2018 & $\begin{array}{c}\text { Sistem } \\
\text { kuesioner online }\end{array}$ \\
\hline
\end{tabular}

Penelusuran data (Tabel 1) setiap tiga tahun (2012, 2013, 2014), dilakukan penelusuran tahun 2015 dengan cara penyebaran kuesioner melalui email attachment, 3 tahun berikutnya (2013, 2014, 2015) ditelusur tahun 2016 dengan metode yang sama, sedangkan mulai 3 tahun (2014, 2015, 2016) dilakukan tahun 2017 dengan metode sistem kuesioner online, 2 tahun kemudian (2016, 2017) telusur tahun 2018 dengan metode yang sama, sampai 2 tahun terkahir $(2017,2018)$ ditelusur tahun 2019 dengan metode yang masih sama kuesioner online.

SMK Negeri 3 Yogyakarta Career Center merupakan pusat karir yang diberi wewenang dan tanggung jawab dalam pelaksanaan Tracer Study di SMK Negeri 3 Yogyakarta. Pada tahun 2015, Bursa Kerja Khusus membentuk Tim Tracer Study SMK Negeri 3 Yogyakarta (saat ini disebut SKAGATA Career Center) sebagai langkah awal dalam mempersiapkan Pelaksanaan Tracer Study di SMK Negeri 3 Yogyakarta.

Dalam setiap tahun penyelenggaraannya, Tracer Study skagata mengalami perkembangan, baik dari sistem, sumber daya, metode pelaksanaan dan juga hasil yang diperoleh. Pada pelaksanaan Tracer Study terbaru tahun 2019, Tracer Study Skagata telah mencapai perolehan data hanya $72 \%$.

Selama ini SMKN 3 Yogyakarta sudah mengembangkan Tracer Study dengan aplikasi berbasis Android, dimana setiap lulusan/tamatan dapat menginformasikan kondisi dirinya apakah sudah bekerja, atau melanjutkan atau berwirausaha melalui HP yang setiap saat ada digengamannya. Hasil dari penelusuran menggunakan aplikasi berbasis android didapatkan masih ada beberapa lulusan/tamatan yang tidak menginformasikan data diri mereka sesuai dengan fakta yang ada. 
Dari permasalahan yang ada, maka perlu adanya pengembangan penelusuran tamatan dengan Pair System yaitu sistem berpasangan siswa baru pada saat Masa Orientasi diberi tugas untuk menelusur alumni, dengan pertimbangan jarak terdekat, satu wilayah bisa keluarahan/ Desa, dan satu kecamatan.

Berdasarkan latar belakang diatas maka rumusan masalah: (1) Bagaimana strategi peningkatan validitas penelusuran lulusan melalui Pair System? (2) Bagaimana peta kebekerjaan lulusan sesuai kompetensi?

Tracer Study dengan metode "Pair System" tidak terbatas pada Sekolah saja, tetapi lebih jauh lagi dapat memberikan informasi penting mengenai hubungan antara dunia pendidikan tinggi dengan dunia usaha dan industri. Tracer Study dengan metode Pair system dapat menyajikan informasi mendalam dan rinci mengenai kecocokan kerja baik. Dengan demikian, Tracer Study Pair System dapat ikut membantu mengatasi permasalahan kesenjangan kesempatan kerja dan upaya perbaikannya. Bagi Sekolah, informasi mengenai kompetensi yang relevan bagi dunia usaha dan industri dapat membantu upaya perbaikan kurikulum dan sistem pembelajaran. Di sisi lain, dunia usaha dan industri dapat melihat ke dalam Sekolah melalui Tracer Study Pair System, dan dengan demikian dapat menyiapkan diri dengan menyediakan pelatihan-pelatihan yang lebih relevan bagi lulusan pencari kerja baru.

Tujuan dari penerapan "Pair System" dalam penelusuran lulusan adalah untuk: (1) Mendeskripsikan strategi peningkatan validitas penelusuran lulusan melalui Pair System. (2) Mendeskripsikan peta kebekerjaan lulusan sesuai kompetensi.

\section{Tinjauan Pustaka}

Sekolah Menengah Kejuruan (SMK) merupakan salah satu lembaga tingkat satuan pendidikan yang berperan menciptakan Sumber Daya Manusia (SDM) berkualitas dan kompeten di bidangnya. SDM yang bermutu adalah tenaga kerja yang siap pakai, yakni tenaga kerja yang menunjukkan penguasaan ilmu pengetahuan, teknologi, dan keterampilan yang tinggi diikuti dengan moral, etika, dan karakter diri yang baik.

Mutu tersebut apabila dimiliki oleh setiap lulusan SMK, maka Indonesia tidak akan kekurangan generasi penerus bangsa mendatang yang potensial. Deskripsi tersebut merupakan gambaran manusia unggul dan merupakan cerminan generasi penerus yang ideal. Penjelasan Undang-undang (UU) Sistem Pendidikan Nasional (Sisdiknas) nomor 20 tahun 2003 mengenai tujuan pendidikan nasional pasal 3 dan penjelasan pasal 15, menyebutkan bahwa SMK merupakan pendidikan menengah yang mempersiapkan peserta didik terutama untuk bekerja pada bidang tertentu.

Di dalam proses pencarian kerja maka dibutuhkan jejaring (networking), pada era digital jejaring aplikasi begitu banyak dikembangkan terutama jejaring sosial yang bisa dimanfaat sebagai media informasi. Jejaring sosial sangat marak sesuai dengan perkembangannya di sekitar kita. Bahkan penggunanya sangat banyak dan meliputi hampir berbagai kalangan usia mulai dari anak-anak, remaja, dan orang dewasa.

Jejaring sosial sendiri mempunyai arti sebagai struktur sosial yang terdiri dari elemenelemen individual atau organisasi. Jejaring ini menunjukan jalan dimana mereka berhubungan karena kesamaan sosialitas, mulai dari mereka yang dikenal sehari-hari sampai dengan keluarga.

Banyak manfaat yang kita dapat dari jejaring sosial. Selain jangkauannya tidak terbatas sehingga kita bisa berkomunikasi dengan siapa saja di mana saja, jejaring sosial juga biasa dimanfaatkan untuk kontrol sosial masyarakat terhadap pemerintah. (Abdillah Yafi Aljawiy $\mathrm{dkk}, \mathrm{tt})$.

Networking atau jejaring dalam komunitas sosial terutama jejaring hal kebekerjaan, informasi loker-lowongan kerja, peluang bisnis, apalagi diera digital yang semuanya serba online. Kompetensi, komunikasi dan networking ini hal yang harus dikuasai.

Keputusan Menteri Pendidikan dan Kebudayaan Nomor 0804J/1993 menyatakan bahwa tujuan Sekolah Menengah Kejuruan (SMK) di Indonesia adalah: (1) menyiapkan siswa untuk memasuki lapangan kerja serta mengembangkan sikap profesional; (2) menyiapkan siswa agar mampu memilih karir, mampu berkompetisi dan mampu mengembangkan diri; (3) Menyiapkan tenaga kerja tingkat menengah untuk mengisi kebutuhan dunia usaha dan industri pada saat ini maupun masa yang akan datang; dan (4) menyiapkan tamatan agar menjadi warga negara yang produktif, adaptif dan kreatif. (Sukamto, dkk, 2000).

Sistem informasi dibangun dalam rangka untuk memudahkan pekerjaan manusia dalam berinteraksi antar manusia, serta mendukung kegiatan untuk pengambilan keputusan dengan cepat. Sistem informasi didefinisikan sebagai suatu sistem yang bersifat manajerial, menyediakan kebutuhan harian olah data transaksi dari kegiatan stategi organisasi dan 
menyiapkan pihak-pihak lain tertentu dalam bentuk laporan-laporan yang diperlukan (Laudon, K. dan Laudon, J., 2007).

Penelusuran tamatan adalah mengusut atau mencari keberadaan tamatan atau lulusan dari lembaga pendidikan. Penelusuran tamatan di SMK memiliki tujuan sebagimana dijelaskan oleh Wuradji, dkk dalam Sriyono, 2016: "Penelusuran lulusan (Tracer study) merupakan bagian penting dari aktivitas sebuah lembaga pendidikan. Melalui penelusuran lulusan akan diperoleh berbagai informasi penting yang sangat bermanfaat bagi lembaga pendidikan yang bersangkutan, bagi para lulusan, dan juga lembaga-lembaga lain yang terkait dengan penyelenggaraan pendidikan. Tracer Study memungkinkan sebuah lembaga pendidikan melacak kondisi lulusan yang dihasilkan dan dari informasi yang diperoleh dapat diambil berbagai kebijakan dan tindakan yang memberikan manfaat bagi para lulusan dan bagi pengembangan lembaga yang bersangkutan.

Data alumni sangat bermanfaat terhadap keberlangsungan di Sekolah Menengah Kejuruan karena orientasi adalah bekerja. Persatuan alumni yang kuat akan memberikan dampak kepada adik kelasnya, bisa memberikan informasi tentang lowongan perusahaan, materi kompetensi yang harus dikuasai untuk bekerja diperusahaan, bisa juga sebagai penghubung antara sekolah dengan perusahaan, sehingga ikatan batin keluarga besar antara siswa, lulusan baru dan alumni yang terdata akan menjaga ekosistem SMK secara terus-menerus.

Berbagai penerapan metode tracer study, penelusuran tamatan yang dilakukan adalah pada saat alumni legalisir diberi angket apakah bekerja, wirausaha dan melanjutkan, sebelum cap tiga jari sebelum siswa lulus diberikan angket telusur, peneraparan metode lapor diri melalui google form, WhatsApp group, Massanger, Instagram, Website. Konsep baru adalah sistem berpasangan, disisipkan diprogram kegiatan masa orientasi peserta didik baru, siswa baru diberi tugas untuk menelusur tamatan/alumni yang berada disekitar lingkungan tempat tinggal, bisa satu dusun, kelurahan, satu kecamatan melalui metode interview, komunikasi dengan media sosial.

\section{Pembahasan}

Bagian awal dalam pembahasan ini akan diuraikan analisis lingkungan mikro, menggambarkan keadaan internal sekolah, dan analisis lingkungan makro mendeskripsikan keadaan eksternal.

\section{Analisis Lingkungan Mikro}

SMK Negeri 3 Yogyakarta adalah salah satu sekolah menengah kejuruan yang terletak di Jalan Wolter Monginsidi 2 Yogyakarta, sekitar 1 $\mathrm{km}$ dari arah utara dari Tugu Yogyakarta, terdiri dari 2 bidang keahlian yakni Teknologi dan Rekayasa, Teknologi dan Informatika, 6 program keahlian yaitu Teknik Konstruksi dan Properti, Teknik Elektronika, Teknik Ketenagalistrikan, Teknik Mesin, Teknik Otomotif dan Teknik Komputer dan Informatika.

Ada 8 kompetensi keahlian: desain pemodelan dan informasi bangunan, bisnis konstruksi dan properti, teknik audio video, tenik instalasi tenaga listrik, teknik pemesinan, teknik kendaraan ringan otomotif, teknik komputer dan jaringan, dan multimedia. Semua mempunyai nilai akreditasi "A". Kompetensi keahlian menghasilkan produk dan jasa sesuai dengan keahlian. Adapun profil dan identitas sekolah dijabarkan berikut:

Profil Sekolah dan Identitas Sekolah: nama resmi sekolah SMK N 3 Yogyakarta, kode registrasi (NSS): 321046004002, NPSN: 20404181, SK Pendirian, nomor SK: 120/Dir Pt/BI/65, tanggal SK: 20 September 1965, Jumlah siswa kelas X: 711, kelas XI: 633, dan kelas XII: 532, total berjumlah 1876 Orang.

Visi, Misi dan Tujuan. Visi :Terwujudnya tamatan yang beriman, unggul, berjiwa wirausaha, berbudaya dan berwawasan lingkungan. Misi: (a) melaksanakan pendidikan dan kegiatan agama sesuai dengan ajaran yang dianut, (b) melaksanakan kegiatan pembelajaran berbasis teknologi informasi dan industri, (c) Mengoptimalkan pembimbingan kegiatan akademik dan non akademik, (d)mewujudkan lingkungan belajar yang berkarakter dan berbudaya khas Jogja, (e) mewujudkan lingkungan yang sehat, sejuk, rapi dan nyaman, (f) Mewujudkan predikat sekolah adiwiyata

Tujuan Sekolah: (a) Terbentuknya kepribadian peserta didik yang bertaqwa dan berakhlaq mulia, (b) terselenggaranya kegiatan pembelajaran berbasis revolusi industri 4.0, (c) terbentuknya pribadi yang berdaya saing di tingkat regional, nasional dan atau internasional (d) terwujudnya lingkungan belajar yang berkarakter dan berbudaya khas Jogja, (e) terciptanya lingkungan yang sehat, sejuk, rapi dan nyaman, (f) tercapainya predikat sekolah adiwiyata, (g) Terwujudnya SMK BLUD.

\section{Fasilitas Sekolah}

Sekolah mempunyai fasilitas yang dibutuhkan: Full Wifi, Perpustakaan, Bengkel Honda, 10 Lab. Komputer Pendukung UN CBT, 
Lab. Audio Video, Lab. Komputer Desain Teknik, Lab. Komputer Multimedia dan Full Wifi, Lab. Teknik, Komputer Jaringan, Ruang Gambar, Bursa Kerja Khusus (BKK), Sarana Ibadah, UKS, Lapangan Olah Raga Indoor - Outdoor, Ruang Sidang 1 (R. Yudhistira Kapasitas 50 orang), Ruang Sidang 2 (R. Kunthi Kapasitas 20 orang), Ruang Aula (R. Bima Kapasitas 300 orang), Balairung Kapasitas 800 orang, Sarana Tempat Olahraga, Badminton, Bola Basket, Wall climbing, Bola Volley, Sepak Bola, Pencak Silat, Futsal, Tenis Lapangan.

\section{Analisis Lingkungan Makro}

Data kemitraan dari Unit Bursa Kerja Khusus (BKK) SMK Negeri 3 Yogyakarta tercatat sebagai unit penyalur tenaga kerja yang bonafid dan terpercaya di lingkungan SMK di Daerah Istimewa Yogyakarta. Bergerak menyalurkan tamatan SMK Negeri 3 Yogyakarta dan tamatan SMK/SMA Negeri/Swasta dari DIY/Luar DIY pada umumnya, untuk mendapatkan pekerjaan di Perusahaan ada 106 mitra industri.

SMK N 3 Yogyakarta membangun kerjasama dengan industri, dunia usaha dan dunia kerja, meliputi sinkronisasi kurikulum, praktik kerja lapangan, magang guru, guru tamu bahkan sampai pada perekrutan serta. Kerja sama dengan akademisi, untuk studi lanjut dan pemantapan kurikulum serta pengembangan teknologi kekinian, program pengenalan industri dan outdoor study berupa kunjungan industri sekitar DIY yang relevan dengan kompetensi keahlian bagi kelas X agar kelak senang dengan pekerjaan yang akan digeluti dan cocok dengan keahliannya.

Program kunjungan IDUKA yang "link and match" di industri besar disekitar Jabodetabek bagi kelas XI, dan atau Industri sekitar Jawa-Bali, yang relevan. Selain menambah wawasan bagi peserta didik, guru-guru produktif juga penjajagan untuk membuka peluang bekerjasama.

Alumni yang sudah mapan sebagai iduka bisa dijadikan hubungan antara adik dan kakak dalam kerjasama PKL, magang, dan perekrutan kerja. Keterikatan dan kepedulian alumni bisa dijadikan program inspirasi atau guru tamu ke sekolah dengan membekali adik-adik kelasnya agar jelas pekerjaan yang diharapkan cocok dengan kompetensinya.

Support dari komite sekolah untuk memberikan sumbangsih baik sebagai mitra penjaga kualitas layanan pendidikan, maupun dukungan materi untuk menunjang rencana kegiatan tahunan sekolah.

Kelas Industri Honda, di kompetensi keahlian Teknik Kendaraan Ringan Otomotif sejak Tahun 2015, dengan daya tampung 18 orang siswa TKR yang diseleksi dari mulai pembelajaran di Sekolah yang didiklat oleh guruguru produktif yang sudah ditrainning di Honda Prospect Motor, kemudian setelah pembelajaran dengan kurikulum Honda atau Industri, maka siswa diterjunkan Praktik Kerja Lapangan di Honda yang disebar di DIY-Jateng, dilanjutkan dengan magang dan sampai pada perekrutan.

Kompetensi Keahlian Teknik Pemesinan dalam waktu dekat merintis kelas Industri dengan PT Yoga Presisi Tecknikatama Indonesia (YPTI), terutama bidang manufacturing. Kurikulum yang digunakan adalah kurikulum industri, dan penerapan budaya kerja di Industri.

\section{Analisis SWOT}

Program sistem berpasangan di dalam penelusuran tamatan (Tracer Study), terlebih dahulu dengan menggunakan analisis SWOT, Kekuatan: Tim Tracer Study artinya ada SDM yang akan selalu berinovasi untuk mengembangkan sistem Tracer Study untuk mendapatkan data lebih Valid, Banyak jejaring sosial yang tersedia Google Form, Instagram, WA Group, twitter, website, dan adanya kegiatan Masa Orintasi Pengenalan Peserta didik baru.

Kelemahan program Pair System adalah jarak penelusuran satu wilayah RT, RW, kelurahan dan kecamatan, ada yang beda kompetensi keahlian, dimungkinkan ada yang satu keahlian, siswa baru belum memiliki SIM Surat Ijin Mengemudi sementara untuk home visit alumni melibatkan orang tua atau teman untuk mengantar, tamatan bekerja diluar DIY sehingga tidak ketemu.

Peluang yang diperoleh data tamatan alumni valid, siswa baru dapat informasi dari lumni tentang pengalamannya waktu sekolah dan pekerjaan, wirausaha atau kuliah, dengan wawancara para alumni siswa menjadi percaya diri, dan komunikasi bisa terjalin lebih erat.

Ancaman yang terjadi terkadang privasi alumni ada yang terganggu apabila memang belum mendapatkan pekerjaan, tidak ketemu langsung dengan alumni, situasi pandemi bisa menjadi kelaster baru penularan Covid-19 pada saat home visit. (Tabel 2) 
Tabel 2. Analisa SWOT Program Sistem Berpasangan - dalam penelusuran tamatan

\begin{tabular}{|c|c|c|}
\hline EKSTERNAL & $\begin{array}{l}\text { Peluang (Opportunities) } \\
\text { 1. Data tamatan/alumni valid } \\
\text { 2. Siswa baru dapat informasi } \\
\text { 3. Karakter: percaya diri } \\
\text { melalui interview alumni } \\
\text { 4. Komunikasi terjalin erat } \\
\text { dan kesinambungan } \\
\text { dengan alumni }\end{array}$ & $\begin{array}{l}\text { Ancaman (Threats) } \\
\text { 1. Privasi tamatan } \\
\text { terganggu/apabila belum dapat } \\
\text { pekerjaan } \\
\text { 2. Transportasi ke tempat } \\
\text { alumni/tamatan (siswa baru } \\
\text { belum punya SIM) } \\
\text { 3. Tidak ketemu langsung dengan } \\
\text { alumni }\end{array}$ \\
\hline $\begin{array}{l}\text { Kekuatan (Strenghs) } \\
\text { 1. Tim Tracer Study (BKK) } \\
\text { 2. Aplikasi Google Form, } \\
\text { instagram, WA Group, } \\
\text { Medsos } \\
\text { 3. Program MOPDB }\end{array}$ & $\begin{array}{l}\text { 1. Mendapat gambaran } \\
\text { tentang iduka } \\
\text { 2. Ikatan alumni untuk meraih } \\
\text { tempat PKL, pekerjaan- } \\
\text { Rekrutmen } \\
\text { 3. Promosi sekolah yang } \\
\text { berkesinambungan }\end{array}$ & $\begin{array}{l}\text { 1. Tidak ada alumni/tamatan } \\
\text { dengan jarak terdekat } \\
\text { 2. Alumni/tamatan berganti nomer } \\
\text { HP, pindah rumah/kos }\end{array}$ \\
\hline $\begin{array}{l}\text { Kelemahan } \\
\text { (Weaknesses) } \\
\text { 1. Jarak Penelusuran } \\
\text { 2. Transportasi siswa baru } \\
\text { yang belum punya SIM } \\
\text { 3. Tamatan bekerja di luar } \\
\text { DIY, luar pulau Jawa }\end{array}$ & $\begin{array}{l}\text { 1. Tamatan / alumni bisa } \\
\text { menguatkan siswa baru } \\
\text { tentang pengalamanya } \\
\text { 2. Karakter percaya diri siswa } \\
\text { lebih kuat melalui } \\
\text { wawancara dan komunikasi }\end{array}$ & $\begin{array}{l}\text { 1. Jarak terdekat tamatan/alumni } \\
\text { tidak sesuai dengan kompetensi } \\
\text { keahliannya } \\
\text { 2. Kekawatiran orang tua saat } \\
\text { terjadi pandemi covid-19, untuk } \\
\text { kunjungan } \\
\text { 3. Data yang diperoleh tidak valid } \\
\text { hanya sekedar pemenuhan tugas }\end{array}$ \\
\hline
\end{tabular}

\section{Perencanaan dan Formulasi Strategi}

Pengumuman kelulusan di bulan Juni, tim tracer study sudah menelusur alumni melalui google form, email perusahaan, email univ, wa massanger, meskipun sudah terdata sistem ijon, sebelum alumni lulus sudah mendapat pekerjaan di Iduka, melalui program job matching dan Carier Day.

Bulan Juli siswa baru mendapatkan program kegiatan masa orientasi pengenalan peserta didik baru (MOPDB), dalam program ini siswa baru diberi tugas untuk mencari alumni/tamatan terdekat bisa tamatan baru, atau alumni satu tahun sebelumnya untuk menelusur apakah alumni bekerja, wirausaha dan melanjutkan.

Penerapan sistem berpasangan ini adik kelas menelusur kakak kelasnya yang sudah lulus, selain untuk mendapatkan data valid juga melatih keberanian mental siswa baru untuk berkomunikasi baik langsung maupun tidak langsung, langsung melalui kunjungan ke rumah alumni, tidak langsung melalui media sosial.

Siswa baru akan mendapatkan informasi tentang pengalaman alumni selama alumni menjadi siswa maupun sebagai pekerja, berwirausaha maupun kuliah. Menjaga kesinambungan antara siswa baru sebagai adik kelas dan alumni sebagai kakak kelas.

Formulasi sebelum penerapan Pair System, alurnya adalah Data tracer tahun sebelumnya, dilakukan penelusuran lulusan baru, metode penelusuran dengan angket syarat cap 3 jari dan legalisir, google form, email perusahaan, email universitas dan WA dan massanger, diperoleh sajian data dan analisa grafik Bekerja, Melanjutkan dan Wirausaha. Formulasi strategi dibagi menjadi dua sebelum dan sesudah penerapan Pair System. (Gambar 2).

Menurut data BPS Februari 2019 sebesar $8,63 \%$, SMK masih menempati peringkat teratas penyumbang pengangguran terbesar, sehingga perlunya penelusuran tamatan oleh tim tracer study untuk membuktikannya, metode yang digunakan selama ini mengandalkan Angket siswa pada saat cap tiga jari, google form, email perusahaan, WA, Masengger, sajian data tidak maksimal, sehingga perlunya sistem baru dengan "Pair System" atau sistem berpasangan siswa baru diberi pasangan menelusur alumni dengan keberadaan wilayah terdekat, tim tracer memberikan peta pasangannya. (Gambar 2).

Siswa baru bisa melakukan kunjungan ke rumah alumni dengan interview, kemudian siswa baru melaporkan hasil penelusurannya kepada tim tracer studi melalui WA grup dan atau email yang telah diberikan, sehingga nantinya bisa didapatkan data yang valid, berapa jumlah alumni yang bekerja, melanjutkan kuliah dan berwirausaha. Serta data yang akurat tentang linerisasi pekerjaan, kuliah ataupun wirausaha. 


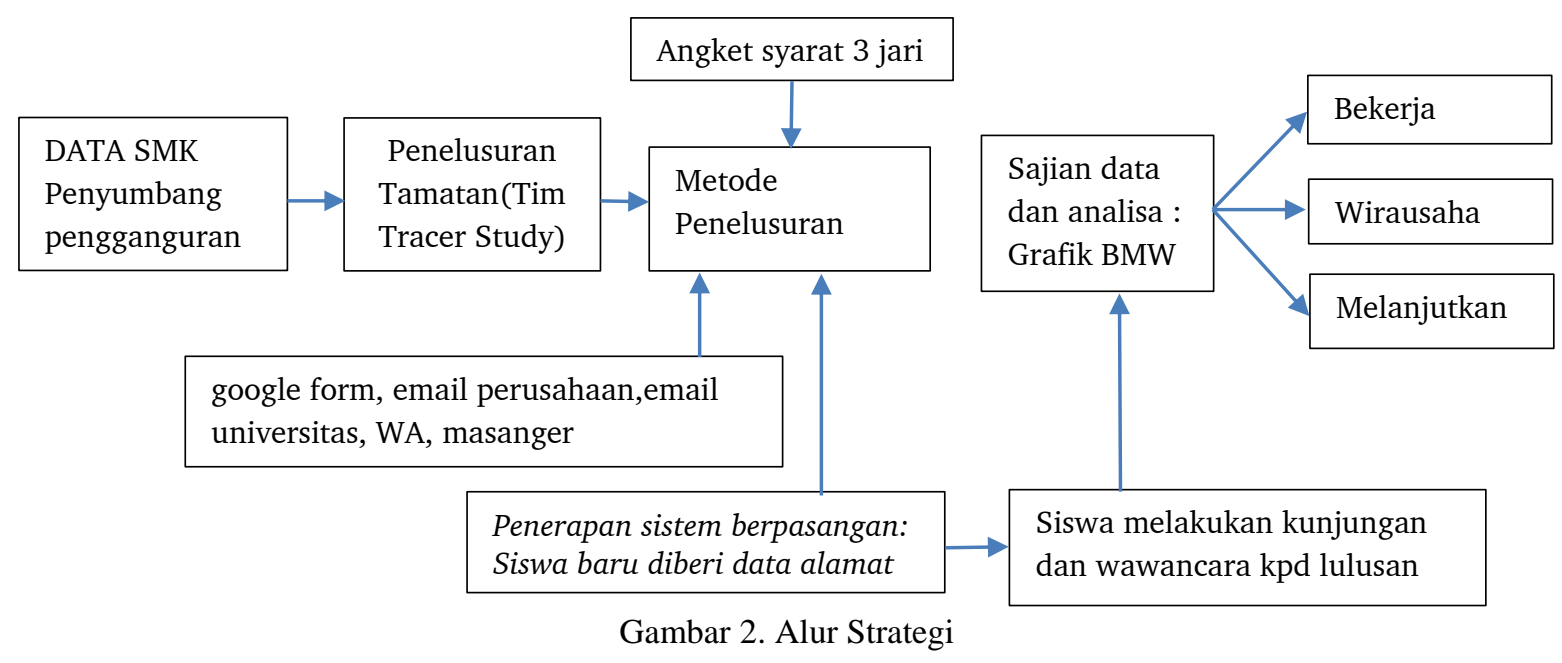

\section{Capaian dan Evaluasi Program Strategi}

Pada Gambar 3. capaian diperoleh Bekerja $52 \%$ (270), Wirausaha 2\% (11) dan Melanjutkan 18\% (93), ketercapaian ini tidak maksimal, karena kesadaran alumni untuk mengisi baik angket maupun google form kurang, bahkan tim penelusuran juga mengirimkan surat kepada akademisi agar memberitahukan alumni SMKN 3 Yogyakarta, kepada pihak sekolah, untuk memperoleh data yang melanjutkan studi.

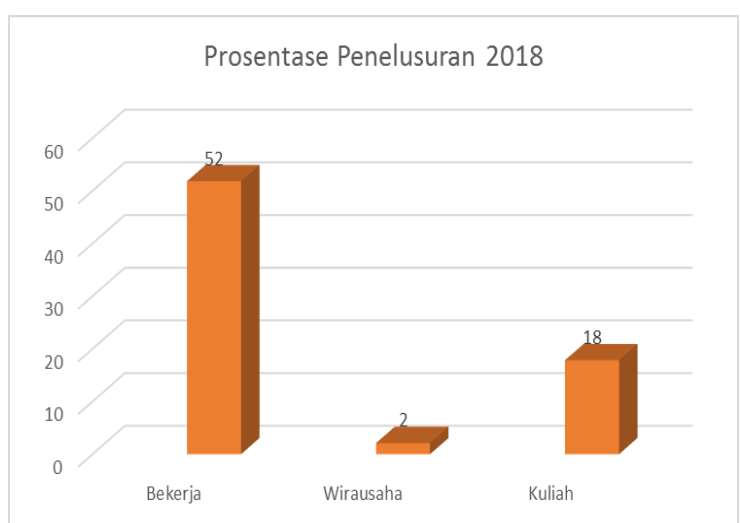

Gambar 3. Penelusuran tamatan Tahun 2018

Dengan melihat hasil penelusuran tersebut maka dikembangkan strategi penelusuran sistem berpasangan "Pair System", dimana siswa baru diberi tugas untuk menelusur alumni, sekaligus sebagai bentuk ikatan antara adik kelas dengan kakak kelas dalam hal ini alumni bisa terjalin, serta siswa baru mendapatkan pengalaman baik pada masa pendidikan saat di sekolah sampai pengalaman saat bekerja.

Strategi "Pair System" yang diterapkan memperoleh hasil (Gambar 4): Penelusuran yang dilaksanakan dari Selasa, 10 November 2020 sampai dengan hari Jumat, 20 November 2020, diperoleh data bekerja $72 \%$ (402), wirausaha $4 \%$ (20) dan melanjutkan 17\% (97).

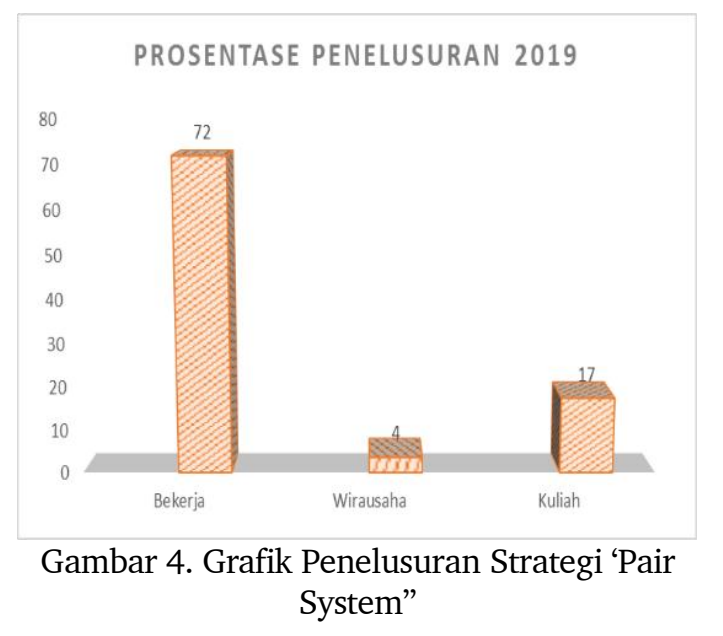

Dari penerapan strategi "Pair System" diperoleh data 93\% (519 dari 560 lulusan), alumni tertelusur, yang dimulai dari 10-20 November 2020. Kesulitan yang terjadi karena alumni, ada yang sudah pindah rumah sehingga alamat yang ditelusur tidak diketemukan. Meskipun sekalipun sudah ditanyakan tetangganya karena riwayat alumni statusnya kos.

Tabel 3. Persentase keterlacakan alumni

\begin{tabular}{lcc}
\hline \multicolumn{1}{c}{ Penelusuran } & 2018 & 2019 \\
\hline Terlacak & $374(72 \%)$ & $519(93 \%)$ \\
Tidak Terlacak & $147(28 \%)$ & $41(7 \%)$ \\
\hline
\end{tabular}

Penelusuran alumni pada Tabel 3 dengan angket dan google form tahun 2018 terlacak $72 \%$ dan tidak terlacak $28 \%$, dan penelusuran tahun 2019 dengan penerapan "Pair System" terlacak 93\% dan tidak terlacak $7 \%$.

Dari Gambar 5, kebekerjaan mengalami kenaikan sesuai kompetensi yakni keahlian Teknik Kendaraan Ringan dari terserap 41\% menjadi 72\%, Teknik Pemesinan 50\% menjadi 70\%, Teknik Instalasi Tenaga Listrik dari 33 menajdi 68\%, Teknik Audio Video 36\% menjadi 68\%, Desain 
pemodelan dan informasi bangunan $43 \%$ menjadi $52 \%$, sedangkan mengalami penurunan bisnis konstruksi dan properti $36 \%$ menjadi $22 \%$, multimedia dari $31 \%$ menjadi $10 \%$ dan Teknik Komputer dan Jaringan dari 50\% menjadi 48\%. Penurunan terjadi karena kecenderungan meningkat ke arah wirausaha.

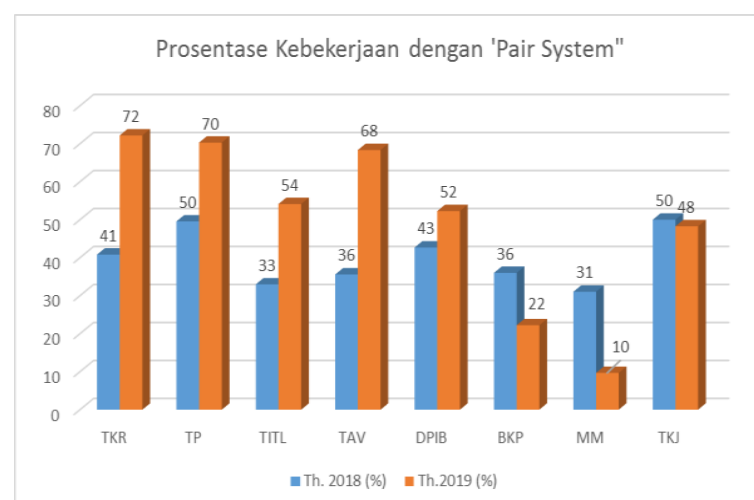

Gambar 5. Persentase kebekerjaan tahun 2018 dan tahun 2019

Hasil implementasi strategi program pengembangan sekolah dengan Pair System dapat meningkatkan penelusuran tamatan dari $72 \%$ menjadi $93 \%$, ada kenaikan $21 \%$, sedangkan hasil kebekerjaan lulusan dengan strategi ini: 270 dari 521 (52\%), menjadi 402 dari 560 (72\%), terjadi peningkatan keberkerjaan dengan gain 20\%, artinya bahwa penerapan strategi ini dapat meningkatkan validitas strategi Pair System dan kebekerjaan lulusan sesuai dengan kompetensinya.

Implementasi strategi Pair System ini dipertahankan dan perlunya ditingkatkan dengan pemetaan sesuai dengan kompetensi keahliannya, prioritas berbasis zonasi dusun, kelurahan dan kecamatan.

Pair System terbukti meningkatkan data lulusan dengan manfaat bagi sekolah mendapatkan informasi alumni, jejaring sosial dengan alumni, menjembatani adik kelas dengan kakak kelasnya, menjaga kekeluargaan dalam ikatan institusi, serta informasi lowongan perusahaan, informasi kompetensi, komunikasi dan networking serta menjaga keseimbangan ekosistem sekolah terutama hal kebekerjaan.

\section{Simpulan dan Saran}

Dari hasil penerapan strategi Pair System diperoleh kesimpulan: strategi Pair System adalah sebuah strategi penelusuran berpasangan dimana siswa baru ditugaskan untuk menelusur lulusan berbasis zonasi tingkat dusun, keluarahan dan kecamatan, hasil implementasi strategi program pengembangan sekolah dengan Pair System dapat meningkatkan validitas penelusuran tamatan dari $72 \%$ menjadi $93 \%$, ada kenaikan $21 \%$. artinya bahwa penerapan strategi ini dapat meningkatkan validitas strategi Pair System, hasil kebekerjaan lulusan dengan strategi ini: 270 dari 521 (52\%), menjadi 402 dari 560 (72\%), terjadi peningkatan keberkerjaan dengan gain $20 \%$.

Kebekerjaan sesuai kompetensi keahlian yakni keahlian Teknik Kendaraan Ringan dari terserap $41 \%$ menjadi $72 \%$, Teknik Pemesinan 50\% menjadi $70 \%$, Teknik Instalasi Tenaga Listrik dari 33\% menjadi 68\%, Teknik Audio Video 36\% menjadi $68 \%$, Desain pemodelan dan informasi bangunan 43\% menjadi 52\%, Pair System memberikan manfaat bagi sekolah, siswa dan alumni dalam ikatan kekeluargaan, kompetensi, komunikasi dan networking, serta menjaga ekosistem kebekerjaan antara adik kelas dengan kakak kelasnya.

Sebaiknya Strategi Pair System bisa dijadikan penugasan bagi siswa baru dalam masa orientasi peserta didik baru, agar data yang diperoleh semakin valid, dan harapan penelusuran bisa mencapai $100 \%$, serta dikembangkan aplikasi laporan hasil Pair System yang bisa menelusur langsung menjadi data bekerja, melanjutkan dan wirausaha, terlacak dan tidak terlacak.

\section{Daftar Pustaka}

Laudon, K. C.; Laudon, J. P. (2007). Sistem Informasi Manajemen. Palgrave, Basingstoke.

Ningsih, R. R. (2016). Potret Lulusan Sekolah Menengah Kejuruan (SMK) Program Keahlian Akuntansi dengan Dunia Kerja. Jurnal Kebijakan Pendidikan. 5(5), 537-547.

Sriyono. (2016).Pengelolaan Bursa Kerja Khusus Pada Penyaluran Tamatan Di SMK Negeri 2 Surakarta. Tesis. Universitas Muhammadiyah Surakarta.

Sukamto dkk. (2000). Peningkatan Manajemen Pemasaran dan Penelusuran Tamatan Sekolah Menengah Kejuruan. Jurnal INOIEKS, Vol 1, No.2, Januari 2000: 101 - 109.

Supriyadi, Adang Suryana dan Rahayu, Endang Sadbudhy. (2020). Pembentukan Karakter Kerja \& Kontrak Belajar. Jakarta : Dir SMK, dirjen vokasi, kemdikbud.

Yafi Aljawiy, Abdillah dan Muklason, Ahmad. (tt). Jejaring sosial dan dampak bagi penggunanya. Jurusan Sistem Informasi, Fakultas Teknologi Infomasi Institut Teknologi Sepuluh Nopember, https://www.researchgate.net/ publication/325044428_Jejaring_Sosial_Dan Internet : _Dampak_Bagi_Penggunanya.

https://www.gamelab.id/news/121pengangguran-terbanyak-disumbang-olehsmk-ini-solusinya di download tanggal 9 November 2020. 